\title{
The Role And Outlet Of Travel Agencies Under Wisdom Tourism -Taking Lijiang As An Example
}

\author{
Ding $\mathrm{Li}^{1, a}$, Shangcheng Zhang ${ }^{1, b}$, Hefang $\mathrm{Liu}^{1, \mathrm{c}}$ and Yajian $\mathrm{Xu}^{1, \mathrm{~d}}$ \\ ${ }^{1}$ Tourism and Culture College of Yunnan University, Lijiang 674100, China;

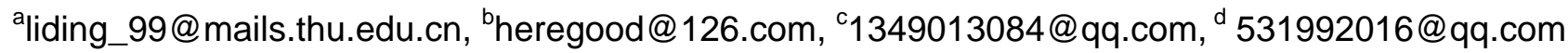

Keywords: business mode, wisdom tourism, challenges, travel agency, role orientation

\begin{abstract}
Taking the travel agency in Lijiang as an example, this paper analyzes the challenges and the specific business modes of travel agencies in wisdom tourism times. Wisdom tourism impact on the business mode of traditional travel agency significantly. Therefore the business mode of traditional travel agencies are unsustainable and several changes must be taken to adapt more and more individual tourists. Many higher demands and standards were put forward by consumers in the process of tourism especially to travel agency. This paper tries to explore a way for the role orientation and the future development of travel agency of Lijiang.
\end{abstract}

\section{Introduction}

\subsection{Review of wisdom tourism}

Wisdom Tourism is to use the portable terminal equipment to actively percept the tourism-related in-formation which can arrange and adjust tourism plan timely by using the mobile cloud computing, Internet of things(IoT)and other new technologies. From the point of view of the user, the wisdom of tourism mainly includes three basic functions are tour guides, shopping guide in tourism and navigation respectively. Deng Huili proposed development strategies basis of Ningxia characteristics and practiced building smart city, strengthen the government support, developing Ningxia wisdom Silk Road Tour, and introducing and cultivating wisdom talents[1]. Qinfei Xu explore to find out the differences of demands between the visitors who are at different ages and education levels[2]. Wiwik Setyaningsih makes a model formulation of the tourist-kampung development through the low-impact-development, to put into realization an eco-green-tourism which supports the city sustainabil-ity[3]. Xinsheng Ke analyzed problems in the in-formatization construction of Chinese cities, combined with advances in information network technology, social needs, and some city informatization instances, proposed development tactics of Chinese city in-formatization[4]. Hai-ling Liu designed and imple-mented a novel personalized smart system that makes tourist spend the least travel cost to reach as many destinations of interest as possible[5]. Thirumalaisamy Ragunathan has proposed the architecture for transport and tourism information system and also developed a prototype system named as Intelligent Transport and Tourism System (ITTS) in Hadoop environment to provide a customized solution for the visitors or tourists who wish to know the information related to transport facility, places of visit in a city, items for purchase, lodging and restaurant details, etc. in a city[6]. Huy Quan $\mathrm{Vu}$ presents a new approach by exploiting the socially generated and user-contributed geotagged photos now made publicly available on the Internet to demonstrate how a dataset constructed from such geotagged photos can help address in fully capturing and understanding the behavior of international tourists as well as provide useful practical implications for destination development, transportation planning, and impact management[7]. Ion Marquesa proposes a specific architecture is composed of a Support Vector Regression (SVR) module for user satisfaction modeling, and an Evolution Strategy (ES) achieving recipe innovation towards user problem solving, providing an underlying innovation layer is able to generate new solutions to yet unknown problems[8]. 


\subsection{Current trends of wisdom tourism}

Along with the rapid development of China's tourism industry, tourism information construction is also carried out in full speed in the major cities of China. The intermediary role of traditional travel agency lost fiercely. Therefore travel agents can defuse the crisis only by innovative methods to create greater value for suppliers and customers. In fact, the core value of travel agency is harmonious with the wisdom of tourism naturally. As we all know, the core value of travel agency products the cost effectiveness, pleasure and sense of safety to visitors. The real travel services are consist of three parties: the tourist, the tourism organization staff and the local residents. These three have contacted each other in harmonious among the process of travel. This is reflect the real value of travel agency. The wisdom of tourism is not just to purchase the new equipment. The core of the wisdom tourism is to take the needs of tourists as the center that visitors can experience the happiness of travel. From the point of travel process, many travel agencies lack innovative power. It only copy the other agencies simply and lead to serious identical in scenic spots, travel path, hotel, shopping, dining thus making those tourists who often go on a tour cannot experience the differences from one place to another place and for those who do not often travel outside, the same line leads to the customer's immediate cost-comparison which make travel agency directly into the price of the Red Sea-the low price competition to attract tourists, laborious and no benefit. Under the auspices of the government, China's travel service industry will be in a new round of strategic restructuring. Future travel agency industry will also be more clearly presented as shown Fig. 1 in the pyramid structure.

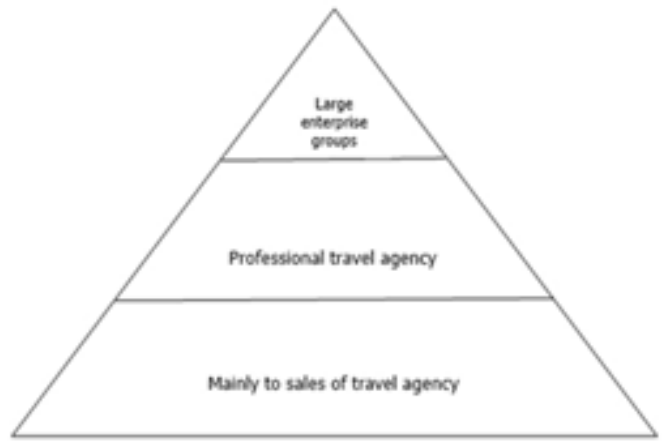

Fig.1 Pyramid Structure of Future Travel

\section{Challenges And Opportunities To Travel Agency}

\subsection{Wisdom tourism challenges to travel agency}

From the perspective of visitor experience: Due to the particularity travel packages, tourists can not visually see before they bought them. The product's look, or to experience live tours that lead to psychological gap existing among tourists is actually generated after purchase travel behavior had been happen. In particular, the emergence of zero or negative fare makes a lot of tourists have fleeced the feeling in the tourism process which directly produce complaints against travel agencies and tour guides. More serious, tourists on a trip will tour with the outbreak of violent impulses, such examples in recent years is not uncommon. In addition, travel agency cannot control its upstream and downstream companies. Tourists traveling in the course, the quality of other co-tenant's travel service can not be monitored in time will lead visitors to experience deterioration thus produce the psychological resistance to travel agency-do not trust, do not rely on so no consumption. While travel market reputation will be affected.

Currently, the online supplier website impact traditional travel agencies of Lijiang enormously. Electricity supplier website bring the capital advantage and number advantages to purchase tours at very low prices from local tour operator then sell on its site in cheap promotional methods that beating a slap on the face of traditional travel agents and making it has not capabilities to hit back . Many hotels or resorts cooperate with various group purchase sites and get good results. More and more resorts and hotels opened its own website can do reserve ticket, hotel's room and shopping and other services online. Visitors can book through the network completely directly to the desired 
services, the mediation role of travel agents are disappearing. But now more and more tourists accustomed to collect information through the Internet and mobile smart devices and to plan travel route, time, travel mode and range. According to the National Tourism Bureau survey, networks, intelligent terminal have become the preferred choice that tourist access to information. About more than $50 \%$ of tourists through these devices to get tourism information. The tourists from abroad to China in 2014, the China Inbound Tourism White Paper released by Google shows more than 70 percent of foreign tourists rely on the network to get travel reservations, and other aspects of experience.

Independent tourist is an important source of tourism agency. But with the gradual improvement of the wisdom of scenic construction, the wisdom make people trip convenience in online that would cause travel mode changed significantly. According to China's travel industry statistics released by the National Tourism Administration deduced, tourist especially young individual who select the traditional travel agencies will be a sharp reduction (report shows from 23-year-old to 45-year-olds is the individual subject, the proportion of about $70 \%$ ). The travel agencies received the ratio of tourist in domestic, inbound and outbound only 5.4\%, $14.8 \%$ and $27.7 \%$ respectively in 2014 . In other words, more than $90 \%$ of domestic tourism, $70 \%$ outbound tourism are not organized by travel agents. The free characters of Individual tourist market is bound to be more rapidly shift to the consumer groups and promote the traditional travel agencies that changed all aspects of tourism services with more innovative way such as marketing, organizing, product design etc. will be urgent need.

\subsection{Wisdom tourism opportunities to travel agency}

The wisdom of tourism greatly expand the visitors the right to choose, but at the same time making the travel in across large-scale region as possible. Traditional travel agencies due to limitations of resource and information that could not beyond a certain area. Therefore it is difficult to achieve large-scale development and it only play the role of tourism intermediaries. In addition, there are different business between the tour-group operators and local tour operators. The wisdom of tourism through new information technologies e.g. cloud computing, Internet of things and others can integrate the tourism resources, business groups, tourism product design and development, sales, tours and other functions of traditional travel agencies business to run on a unified information technology platform that break the regional barriers.

\section{Suggestions}

i The travel agency may be take the consumer's point of view of tourist willingness at first from the process of initiative idea to going to a tour to consult a travel agency and the final trip. For the whole operation process, the travel enterprise should provide all the services and divide these services to each step which link each other. There are a set of refined policies and rules will be formed. Then a system of rules will be cured and implement and formed a set of Q\&A series to ensure each employee's actions under the control of rule-based and retrace the steps.

ii Cooperation with financial institutions. Travel agencies can also cooperate with banks to develop interest-free installments tourism business, in order to attract tourists who want to travel and have time but temporarily do not have sufficient funds to participate in the travel agency organization of tourism activities. Cooperation with financial institutions will become a new trend in the development of travel agents in the future.

iii Development of business of travel service. With China's business activities have become increasingly frequently the number of enterprises dramatically increase their business trip. More and more companies are looking to outsource travel through the whole way to achieve standardized travel reimbursement system to reduce travel costs. Based on this situation, travel agencies can develop the travel business. In addition, travel agents can also make full use of their own advantages to take the initiative to undertake various industry conferences, annual meeting, exhibition and other development of exhibition business.

iv Enhanced personalized service. At present in the process of travel agency business, only a few mode of travel agency in modern business. The vast of travel agencies operate in single 
mode-booking ticket of car, ship or plane; reception and organization travel team and supplying limited service. So, in the current era of wisdom tourism, travel agencies need to develop innovative business products in varieties way.

\section{Summary}

Building wisdom travel agency. Under the influence of the era of wisdom tourism, travel agencies should make full use of mobile Internet technology to develop specialized features of the wisdom of APP software. Whether it is booking, tour guide or share APP that should emphasize technology upgrade. In addition, travel agencies should change operational mode and use more prominent technology and focus on human nature to accelerate interaction with consumer, to create a good foundation of tourism information, to integrate tourism resources, tourism products development and sales, and tourism services and other business and process of information to a plat in online ,intelligent, efficient, fast, convenient and low cost scale way to operate, to create a win-win situation for tourists and travel agents. Finally, travel agencies realize the wisdom mode hence to promote the transformation of the entire travel agency industry in sustainable way.

Once there is a set of smart travel service system in support as backbone that tourists purchase travel products to obtain authentic information and enjoy the service standards that are the actions large travel agencies do them for visitors. Travel agency can play its advantage to provide professional service for each travel process. Even after the end of the trip, it should also establish the database of tourist archives. Through the database is be analyzed and mined to find out the basis of personalized service and to discover new sales opportunities; through e-mail, direct mail, mailing lists, tourists forum travel agents have established interactive communication with visitors, to strive for customer lifetime.

\section{Acknowledgements}

The research work was supported by Foundation of Bureau of Science and Technology Lijiang, Yunnan Provincial under Grant No. ljs2013-09 and scientific research foundation of Tourism and Culture College of Yunnan University under Grant No. 2013xy08.

\section{References}

[1]. DENG, H., MIAO, H., \& MA, J. (2015). Development status and strategy for Ningxia wisdom tourism. Ningxia Engineering Technology, 2, 025

[2]. Xu, Q., \& Ke, W. (2015). The Construction of Wisdom Scenic Area Research Based on Tourist Experience: A Case of Summer Palace. In LISS 2015 (pp. 675-680). Springer Berlin Heidelberg.

[3]. Setyaningsih, W., Iswati, T. Y., Nuryanti, W., Prayitno, B., \& Sarwadi, A. (2015). Low-Impact-Development as an Implementation of the Eco-Green-Tourism Concept to Develop Kampung towards Sustainable City. Procedia-Social and Behavioral Sciences, 179, 109-117.

[4]. Ke, X., \& Sun, Q. (2015). Problems and Strategies in the Process of China's City Informatization. In LISS 2013 (pp. 397-402). Springer Berlin Heidelberg.

[5]. Liu, H. L., Li, J. H., \& Peng, J. (2015, July). A novel recommendation system for the personalized smart tourism route: Design and implementation. In Cognitive Informatics \& Cognitive Computing (ICCI* CC), 2015 IEEE 14th International Conference on (pp. 291-296). IEEE.

[6]. Ragunathan, T., Battula, S. K., Vedika, J., Anitha, V., Tarun, T., Prasad, M. S., \& Kalyani, M. U. (2015). ITTS: Intelligent Transport and Tourism System. Procedia Computer Science, 50, 191-196. 
[7]. Vu, H. Q., Li, G., Law, R., \& Ye, B. H. (2015). Exploring the travel behaviors of inbound tourists to Hong Kong using geotagged photos. Tourism Management, 46, 222-232.

[8]. Marques, I., Graña, M., Kamińska-Chuchmała, A., \& Apolloni, B. (2015). An experiment of subconscious intelligent social computing on household appliances. Neurocomputing. 